Cochrane Database of Systematic Reviews

\title{
Oxcarbazepine in the maintenance treatment of bipolar disorder
} (Review)

Vasudev A, Macritchie K, Watson S, Geddes J, Young AH

Vasudev A, Macritchie K, Watson S, Geddes J, Young AH.

Oxcarbazepine in the maintenance treatment of bipolar disorder.

Cochrane Database of Systematic Reviews 2008, Issue 1. Art. No.: CD005171.

DOI: 10.1002/14651858.CD005171.pub2.

www.cochranelibrary.com 
HEADER

ABSTRACT

PLAIN LANGUAGE SUMMARY

BACKGROUND

OBJECTIVES

METHODS

RESULTS

DISCUSSION

AUTHORS' CONCLUSIONS

ACKNOWLEDGEMENTS

REFERENCES

CHARACTERISTICS OF STUDIES

ADDITIONAL TABLES

WHAT'S NEW

HISTORY

CONTRIBUTIONS OF AUTHORS

DECLARATIONS OF INTEREST

SOURCES OF SUPPORT

INDEX TERMS

\section{TABLE OF CONTENTS}

1

1

2

3

3

3

6

7 
[Intervention Review]

\section{Oxcarbazepine in the maintenance treatment of bipolar disorder}

Akshya Vasudev ${ }^{1}$, Karine Macritchie ${ }^{2}$, Stuart Watson ${ }^{3}$, John Geddes ${ }^{4}$, Allan H Young 5

${ }^{1}$ Castleside Offices, Centre for Health of the Elderly, Newcastle Upon Tyne, UK. ${ }^{2}$ Department of Psychiatry, University of British Columbia, Vancouver, Canada. ${ }^{3}$ Department of Psychiatry, Leazes Wing, Royal Victoria Infirmary, Newcastle-upon-Tyne, UK. ${ }^{4}$ Department of Psychiatry, University of Oxford, Oxford, UK. 5Department of Psychiatry, University of British Columbia, Vancouver, Canada

Contact address: Allan H Young, Department of Psychiatry, University of British Columbia, Suite 430 Strangway Building, 5950 University Boulevard, Vancouver, V6T 1Z3, Canada. allan.young@ubc.ca.

Editorial group: Cochrane Common Mental Disorders Group

Publication status and date: Edited (no change to conclusions), published in Issue 1, 2010.

Citation: Vasudev A, Macritchie K, Watson S, Geddes J, Young AH. Oxcarbazepine in the maintenance treatment of bipolar disorder. Cochrane Database of Systematic Reviews 2008, Issue 1. Art. No.: CD005171. DOI: 10.1002/14651858.CD005171.pub2.

Copyright @ 2010 The Cochrane Collaboration. Published by John Wiley \& Sons, Ltd.

\section{A B S T R A C T}

\section{Background}

Some studies have suggested that oxcarbazepine has a role in preventing episode recurrence in bipolar affective disorder. This review attempted to investigate the existing evidence from randomised controlled trials for its use in the maintenance treatment of this illness.

\section{Objectives}

To review the efficacy of oxcarbazepine, relative to placebo and other agents, in the prevention of affective episodes of bipolar affective disorder. The efficacy of oxcarbazepine was considered in terms of episode recurrence, general and social functioning. Adverse effects, overall acceptability to participants and mortality were also considered.

\section{Search methods}

CCDANCTR-Studies and CCDANCTR-References were searched on 7/11/2007. Medline, CENTRAL, EMBASE and PsycINFO were searched in March 2007. Specialist journals and conference proceedings were handsearched. Reference lists of relevant papers and major textbooks of affective disorder were checked. Authors, experts in the field and pharmaceutical companies were contacted requesting information on published or unpublished trials.

\section{Selection criteria}

Randomised controlled trials comparing oxcarbazepine with placebo or alternative agents, where the stated intent of intervention was the maintenance treatment of bipolar affective disorder were sought. Participants with bipolar disorder, male and female, of all ages, were included.

\section{Data collection and analysis}

Data were extracted from the original reports individually by two review authors. The methodological quality of included studies was assessed individually by two review authors. The main outcomes were the efficacy of oxcarbazepine maintenance treatment in preventing or attenuating further episodes of bipolar affective disorder (including its efficacy in rapid cycling disorder), the acceptability of oxcarbazepine treatment to participants, the prevalence of side-effects, and mortality, if any, on oxcarbazepine treatment. Where appropriate, data concerning outcome measures and adverse effects were to be extracted from the studies and analysed using Review Manager software. 


\section{Main results}

Two randomised controlled trials were found that met the methodological criteria for inclusion in the review. However, they did not report data with sufficient clarity to allow their confident extraction for inclusion in the meta-analysis. Findings from the two studies were presented descriptively.

\section{Authors' conclusions}

There is an insufficient methodologically rigorous evidence base to provide guidance on the use of oxcarbazepine in the maintenance treatment of bipolar disorder. Given the need for more efficacious therapeutic agents, there is a need for good quality randomised controlled trials examining the therapeutic potential of this and related agents in bipolar disorder.

\section{PLAIN LANGUAGE SUMMARY}

\section{Oxcarbazepine in the maintenance treatment of bipolar disorder}

Some studies have suggested that oxcarbazepine, an anti-convulsant, may have a role in preventing episode recurrence in bipolar affective disorder. This systematic review investigated the efficacy and acceptability of oxcarbazepine compared to placebo and other agents in the maintenance treatment of bipolar disorder. Two randomised controlled trials were found that met the methodological inclusion criteria. However, in both cases, data were reported with insufficient clarity to be confidently extracted for inclusion in a meta-analysis. Currently, there is insufficient evidence on which to base any recommendations on the use of oxcarbazepine in the maintenance treatment of bipolar illness, either in monotherapy or as an adjunctive treatment. There is need for good quality randomised controlled trials examining the efficacy and acceptability of oxcarbazepine in the maintenance treatment of bipolar disorder. 


\section{B A C K G R O U N D}

Bipolar affective disorder is a chronic disorder with a life time prevalence of 1 to 5\% (Akiskal 2000). Although classically it is thought to manifest as repeated manic, depressed or mixed episodes with complete inter-episode recovery, there are high rates of chronicity with impact on social and occupational development (Angst 2000). Agents used in the treatment of bipolar disorder should be efficacious in treating affective episodes of any type and/or in preventing their recurrence when used in maintenance therapy.

Lithium is the agent in longest use. It remains a first choice in the treatment of bipolar disorder, for both acute and maintenance treatment (Goodwin 2003). However, the response to lithium treatment is often unsatisfactory (Bowden 1996). The most problematic adverse effects are those of acute toxicity, renal impairment and hypothyroidism. One major difficulty is that the serum concentration of lithium required to produce a therapeutic effect is close to the level which produces symptoms of toxicity -indeed toxicity may occur within the therapeutic range. A high degree of vigilance is required, and serum lithium levels must be monitored carefully (BNF 2007). Another practical difficulty is that it may precipitate episode recurrence on drug withdrawal, making its beneficial effects for the non-compliant patient doubtful (Goodwin 1994). The anticonvulsants carbamazepine, valproate and lamotrigine are often used as adjunctive and alternative treatments to lithium in both acute and maintenance treatment. The evidence for their use in these contexts has been reviewed in the compiling of recent guidelines (NICE 2006; Yatham 2005; Yatham 2006). A recent systematic review of randomised controlled trials of maintenance treatment in bipolar disorder (Smith 2007) found that valproate and lamotrigine were efficacious in preventing episode recurrence. However, even with these advances, treatment resistance persists and new medications are required.

Little evidence exists regarding the efficacy of carbamazepine in maintenance treatment. One small randomised controlled trial was reported by the authors as evidence of efficacy (Okuma 1981), but the authors of a systematic review found the relative risk of recurrence on carbamazepine treatment was not significantly reduced (Smith 2007). Open label and randomised controlled trials suggest that oxcarbazepine, a chemical derivative of carbamazepine, may be efficacious in the treatment of acute episodes (See Hirschfeld 2004 for review). There is also limited evidence from an open label acute and continuation study that it may be an effective adjunctive agent to lithium in longer term treatment (Benedetti 2004).

Oxcarbazepine has potential advantages over carbamazepine in that it does not induce liver enzymes as carbamazepine does (Isojarvi 1994), and so the possibility of drug interactions is reduced. It causes rashes less frequently (Dietrich 2001). However, some $25-30 \%$ of participants with hypersensitivity to carbamazepine are also hypersensitive to oxcarbazepine (Dietrich 2001). Other idiosyncratic reactions such as agranulocytosis, hepatic reactions, and aplastic anaemia associated with carbamazepine are also lower (PDF 2001). Hyponatremia has been reported to occur with higher frequency in oxcarbazepine compared to carbamazepine (Dong 2005), and so blood monitoring is required (PDF 2001).
In this systematic review, the evidence base for the use of oxcarbazepine in the maintenance treatment of bipolar affective disorder is examined. For the purposes of this review, maintenance treatment is defined as an intervention that is intended to prevent or attenuate manic, depressive and mixed episodes. Recurrence is used to denote a new episode of illness, although it is recognised that due to the chronicity of symptoms in bipolar disorder, the term relapse may be more appropriate (see Goodwin 2003).

\section{OB JECTIVES}

1. To determine the efficacy of oxcarbazepine compared to placebo or an alternative drug in maintenance treatment

1.1 in preventing or attenuating manic, depressive and mixed episodes of bipolar affective disorder.

1.2 in preventing or attenuating episodes of bipolar affective disorder participants with rapid cycling disorder.

1.3 on participants general health and social functioning as measured by the clinician's global impression, by global impression of the subject, family members of significant others and by employment and marital stability.

2. To review the acceptability of maintenance oxcarbazepine treatment to participants, measured by numbers of participants failing to complete studies, their reasons for dropping out, by measures of compliance and by reference to participants expressing views regarding treatment.

3. To investigate the adverse effects of oxcarbazepine treatment, including general prevalence of side effects. Specific unwanted effects were also studied.

4. To determine overall mortality rates, if any, on oxcarbazepine maintenance treatment.

\section{METHODS}

\section{Criteria for considering studies for this review}

\section{Types of studies}

Prospective randomised controlled trials comparing oxcarbazepine maintenance treatment with placebo or alternative drug treatment in bipolar affective disorder were to be considered for inclusion in the review. Maintenance treatment was defined as treatment instituted specifically or mainly to prevent further episodes of illness. Discontinuation trials, in which some participants who had received oxcarbazepine prior to randomisation were switched to placebo, would be analysed separately because of the unknown risk of recurrence precipitation in this group. In trials combining acute and maintenance phases of treatment, if possible, maintenance data would be extracted.

\section{Types of participants}

Trials involving males and females of all ages, with a diagnosis of bipolar affective disorder approximating to ICD-10 Code F31 ${ }^{\star}$ (WHO 1992) and/or DSM IV 296* (APA 1994), were included. This definition of diagnosis included previous versions of International Classification of Diseases and the Diagnostic and Statistical Manual.

All subtypes of bipolar disorder (types I and II, other and rapid cycling disorder-defined by four or more affective episodes per year) were included. Where trials involved heterogenous groups of participants, in particular participants with schizoaffective disorder 
and recurrent unipolar depression (diagnoses approximating to ICD-10 F25 and DSM IV 295.70, and ICD-10 F33 and DSM IV 296.3, respectively), data would be separated into diagnostic groups if randomisation had been so stratified. Where such separation was impossible, the studies would be included but a sensitivity analysis would be conducted to examine the effect of their inclusion on our results. If such separation of heterogenous group data proved impossible, it was planned to extract information from these studies only if at least $80 \%$ of randomised participants had a bipolar diagnosis.

Where the information was available, previous treatment and patient response to previous treatment was to be noted.

\section{Types of interventions}

Trials examining oxcarbazepine as a maintenance treatment were eligible for inclusion. Maintenance treatment was defined as treatment instituted specifically or mainly to prevent further episodes of illness (see Background). Where trials combined acute and maintenance phases of treatment, if possible, maintenance data would be extracted.

Comparison of maintenance oxcarbazepine treatment with:

1. placebo

2. alternative agent

3. combination treatment

\section{Types of outcome measures}

For each type of episode, a separate analysis was planned according to the criteria listed below. All outcome measures would be evaluated over the period from the introduction of treatment to the end of study period.

\section{Primary outcome}

Number of participants suffering an affective episode by the end of the study period

\section{Secondary Outcomes:}

For each type of affective episode the following outcome measures would be estimated

1. Efficacy of oxcarbazepine in preventing/attenuating further episodes of affective disorder, measured by:

Recurrence of all affective episodes:

-admission to hospital: time to next admission the number of admissions during trial period.

-institution of additional treatment for affective episode and time to institution.

-number of episodes during trial.

Recurrence of manic episodes:

-admission to hospital: time to next admission, the number of admissions during trial period.

-institution of additional treatment for manic episode and time to institution.

-number of episodes during trial period.

Recurrence of mixed affective states:

-admission to hospital: time to next admission, the number of admissions during trial period. -institution of additional treatment for mixed affective state and time to institution.

-number of episodes during trial period.

Recurrence of depressive episodes:

-admission to hospital: time to next admission, the number of admissions during trial period.

-institution of additional treatment for depressive episode and time to institution.

-number of episodes during trial.

Studies examining rapid cycling bipolar disorder were to be considered separately. Efficacy of oxcarbazepine in preventing/ attenuating episodes in rapid cycling disorder was to be measured by recurrence of affective episodes:

-admission to hospital.

-institution of additional treatment for affective disorder.

-length of well period, expressed in cycle lengths.

2. General and social functioning were to be measured by:

-clinical global impression of the clinician.

-global impression of the subject, family or significant other(s). -employment during study period.

-separation/divorce during the study period.

3. Acceptability of oxcarbazepine treatment, measured by: -subjects dropping out of treatment during the study period. -measures of compliance: completion of the trial was taken as a specific

surrogate marker of acceptability.

-subject reports of satisfaction or otherwise with treatment.

4. Adverse effects:

Subjects experiencing troublesome side effects of any nature

Subjects experiencing specific adverse effects which include

Dizziness

Diplopia

Somnolence

Fatigue

Nausea

Vomiting

Ataxia

Abnormal Vision

Abdominal pain

Tremor

Dyspepsia

Abnormal gait

Cases of teratogenicity.

Deranged blood biochemical markers

5. Mortality Rates:

-Overall mortality rates during the study period.

-Mortality excluding suicide and verdicts of undetermined death.

-Suicide and verdicts of undetermined death.

\section{Search methods for identification of studies}

\section{Electronic searches}

CCDANCTR-Studies - searched on $7 / 11 / 2007$

Intervention = Oxcarbazepine

CCDANCTR-References - searched on 7/11/2007 
Free-text $=$ Oxcarbazepin ${ }^{\star}$ or trileptal

The following databases were searched using Cochrane Collaboration search algorithms (See Additional Tables) for trials on the maintenance of oxcarbazepine in bipolar disorder:

1.1 The Cochrane Central Register of Controlled Trials (CENTRAL). 1.2 MEDLINE (1966-March 2007)Table 1

1.3 EMBASE (1980-March 2007) Table 2

1.4 PsycINFO (1996-March 2007) Table 3

The following terms were used for oxcarbazepine in our database search: oxcarbazepine, trileptal

\section{Reference lists}

The reference lists of all identified randomised controlled trials were checked. Cross references from other published papers including open label studies and case note analysis were also checked. Textbooks on affective disorders were also checked.

\section{Hand searching}

Comprehensive Psychiatry (1960 - 2006) was hand searched. We had mentioned in our protocol that the journal Bipolar Disorder, would also be hand searched. However, this journal is now hand searched in the compilation of the CCDAN registers.

The annual conference proceedings of the American Psychiatric Association (2001 to 2006), CINP (2001 to 2006) and the British Association of Psychopharmacology (2001 to 2006) were hand searched.

Textbooks on affective disorders including Essential Psychopharmacology of Depression and Bipolar Disorder, Oxford Textbook of Psychiatry, and Textbook of Psychopharmacology were also checked.

\section{Personal communication}

The authors of significant papers over the last five years were identified from authorship lists. They, and other experts in the field, were contacted and asked of their knowledge of other studies, published or unpublished relevant to the review. Pharmaceutical companies marketing oxcarbazepine products were requested to provide relevant published and unpublished data (see CCDAN group policy).

No language restriction were applied within the limitations of the search tools.

\section{Data collection and analysis}

\section{Selection of trials}

Studies generated by the search strategies were independently reviewed to ensure that they met the previously defined inclusion criteria by two reviewers (AV and KM). There were no disagreements.

\section{Data extraction}

For trials which met the inclusion criteria of the meta-analysis, two reviewers ( $\mathrm{AV}$ and $\mathrm{KM}$ ) attempted to extract the data concerning participant characteristics, intervention details and outcome measures.

\section{Assessment of methodological quality of included studies}

The quality of each included randomised controlled trial was assessed independently by two authors (SW and AHY), based on quality criteria specified by Schulz and Jadad (Jadad 1996; Schulz 1995). The following factors were studied:

3.1 Minimisation of selection bias - a) was the randomisation procedure adequate? b) was the allocation concealment adequate?

3.2 Minimisation of attrition bias - a) were withdrawals and dropouts completely described? b) was the analysis by intentionto treat?

2.2 Minimisation of detection bias - were the outcome assessors blind to the intervention?

We planned a sensitivity analysis based on classification of the studies into three categories (Cochrane Handbook for Systematic Reviews of Interventions (Higgins 2005): A - low risk of bias: all quality criteria met; $\mathrm{B}$ - moderate risk of bias: one or more of the quality criteria only partially met; $\mathrm{C}$ - high risk of bias: one or more quality criteria not met; as well as exploring the effect of the failure to satisfy the quality criterion. Should any disagreements arise, calculation of the level of inter-rater agreement using the kappa statistic (Cohen 1960; Fleiss 1981) was planned for quality assessment, with any variation in assessment by the authors resolved through discussion.

\section{Data Analysis}

Extracted data would be entered into the Review Manager program by two reviewers (AK and KM) for analysis.

\section{Measures of treatment effect}

For binary efficacy outcomes, a pooled relative risk (RR) (with $95 \%$ confidence intervals $(\mathrm{Cl})$ ) would be calculated using a fixed effects model. Random effects models would be used to investigate the sensitivity of results to the choice of statistical method. For continuously distributed outcomes, the weighted mean difference or standardised mean difference would be calculated as appropriate.

\section{Management of missing data and skewed data}

It was planned to use intention-to-treat (ITT) data when they were available. When this was not possible, end-point data for trial completers would be used. When skewed data were identified (following inspection using recommended methods for detecting skewness from summary data (Altman 1996)), they would be reported descriptively. Non-quantitative data would be presented descriptively. Outcomes concerning relapse/recurrence of mood disorder would be analysed excluding data from studies of discontinuation design. Data from these studies were to be analysed separately, to assess the effects of oxcarbazepine discontinuation.

\section{Assessment of heterogeneity}

Heterogeneity between studies would be assessed using the Q statistic (DerSimonian 1986) and by visual inspection. If significant heterogeneity was identified, potential sources would be investigated.

\section{Sub-group analyses and investigation of heterogeneity}

Sub-group analyses would be performed when appropriate to assess the outcomes of oxcarbazepine treatment of mixed mood episodes, mood disorder with psychotic features, rapid cycling disorder, schizo-affective disorder and recurrent unipolar depression (Oxman 1995). Sub-group analyses would also be performed to assess the efficacy of oxcarbazepine treatment in those who had previously failed to respond to treatment. 


\section{Sensitivity analyses}

It was planned to perform sensitivity analyses, excluding studies of lower methodological quality, to assess the robustness of the results.

\section{Publication bias}

Where sufficient studies were available for inclusion, the presence of publication bias would be examined through constructing a funnel plot.

\section{RES U L T S}

\section{Description of studies}

\section{Included studies}

We found two studies that could be considered for inclusion in the review (Cabrera 1986; Wildgrube 1990). Details of the characteristics of these studies are given in the Table 'Characteristics of included studies' and an account of each of the trials is given below. Two studies were excluded (Reinstein 2003; Wagner 2006b).

\section{Ongoing studies}

We found no reports of on-going studies of oxcarbazepine in bipolar disorder in our searches. No studies await further assessment.

\section{Study types and duration}

Cabrera 1986 conducted a 36 month randomised controlled study and Wildgrube 1990 conducted a similar 31 month study of maintenance treatment in bipolar disorder and schizoaffective disorder.

\section{Intervention}

Cabrera 1986 randomised ten participants to either oxcarbazepine ( $n=4,2$ males and 2 females; age range 21-61, mean age 41.5) or lithium ( $n=6,4$ males and 2 females; age range 22-50, mean age 31). Four participants were included separately in a nonrandom group and were offered oxcarbazepine. Wildgrube 1990 randomised fifteen participants to either oxcarbazepine $(n=8,5$ males and 3 females, age range 21-68 years, mean age 44.3) or lithium ( $n=7,4$ males and 3 females, age range 22-50 years, mean age 31). Five other participants were treated with oxcarbazepine after unsatisfactory treatment or if they had severe side-effects with lithium.

\section{Dosing}

Cabrera 1986 initiated oxcarbazepine at a fixed dosing regimen of $300 \mathrm{mg} /$ day in first week increasing to $600 \mathrm{mg} /$ day and 900 $\mathrm{mg} /$ day in the second and third weeks respectively. Lithium was administered to maintain serum concentration of 0.6 to $0.9 \mathrm{mmol} /$ litre. Wildgrube 1990 did not report the initiating dosages of either oxcarbazepine or lithium. Oxcarbazepine was administered at an average dose of $900 \mathrm{mg} /$ day during the first year with a maximum dose of $2400 \mathrm{mg}$. The dose of lithium was adjusted to maintain therapeutic levels which were not detailed.

\section{Participants}

The study participants in both groups had a diagnosis of either bipolar disorder or schizoaffective disorder. Both studies used ICD-9 to provide diagnostic criteria. Neither of the studies presented data on co-morbidities. Neither study described the setting of the study and whether the participants were inpatients or out-patients. Neither of the studies mention about other medications being prescribed to the participants prior to randomisation.

The inclusion criteria were not detailed in either studies. Exclusion criteria were listed in both published papers and included haematological disorders, hypersensitivity reactions to intervention agents, alcohol or drug addiction and pregnancy.

In the Cabrera 1986 study the mean number of hospital admissions prior to randomisation, were 4.8 (range 4-5) for the oxcarbazepine group and 3.8 (range 2-6) in the lithium group. In the study by Wildgrube 1990, participants on oxcarbazepine had been diagnosed with the illness for a longer period compared to those on lithium (mean duration 12.9 years versus 6 years respectively), but the number of previous admissions were not mentioned.

\section{Outcomes}

\section{Primary Outcome}

Both studies considered an affective recurrence (mania, depression or mixed state) as the primary outcome measure.

\section{Secondary Outcome}

Both studies mentioned adverse effects as secondary outcome measures.

\section{Risk of bias in included studies}

Two review authors independently assessed quality (AHY and SW). There were no disagreements, the kappa statistic was not utilised.

\section{Randomisation and allocation concealment}

Both the studies (Cabrera 1986; Wildgrube 1990) were judged to have inadequately concealed treatment allocation (grade C). Neither of the studies mention details about methods of randomisation or allocation concealment. Both studies had additional open label, non-randomised arms. Wildgrube 1990 did not report data from participants according to method of allocation, making extraction of randomised data impossible.

\section{Blinding}

Neither study described any blinding procedures and both studies included patients on open label, non-randomised treatment.

\section{Power calculation}

Neither study reported power calculations.

\section{Intention to treat analysis and per-protocol analysis, missing data}

Cabrera 1986 analysed the data from all participants in the groups to which they were allocated. For Wildgrube 1990, it is not clear whether data from all participants were reported according to allocated treatment because of inconsistencies in the published account.

\section{Discontinuation and attrition rates}

Both studies reported discontinuation rates. In the Cabrera 1986 study, a thirty six month follow up was planned, but all patients dropped out prior to that. All participants on oxcarbazepine $(n=4$, 100\%) dropped out (between 6 to 22 months). Though the text mentions that only one $(17 \%)$ of the patients on lithium dropped out, the life chart map suggested that all other participants on lithium dropped out of the study between 7 to 16 months post randomisation. 
Wildgrube 1990 reported similarly high discontinuation rates in participants on oxcarbazepine (67\%) and lower rates for patients on lithium (33\%). Again, the results from the randomised and the open-label groups were presented together. Causes of dropouts were: oxcarbazepine ( $n=9$, one developed leucocytopenia, one had cancer, two rejected treatment, one had no therapeutic effect and one was non-compliant), lithium ( $n=9$, one had general emotional indifference, one intended pregnancy and one rejected treatment)

\section{Compliance measure}

Neither of the studies used measures to assess compliance with treatment, other than the dropout rates listed above.

\section{Funding}

Sources of funding were not detailed in the published accounts

\section{Publication status}

Both studies were published in peer reviewed journals.

\section{Effects of interventions}

Both included studies (Cabrera 1986; Wildgrube 1990) attempted to assess the prophylactic efficacy of oxcarbazepine in persons with bipolar disorder. For the purposes of this review, they were categorised as 'included studies'. However, in both cases, the study method and data were reported with insufficient clarity to allow extraction and inclusion in the meta-analysis. This was the case despite help from one of the authors (Wildgrube 1990), who generously reviewed data from work undertaken several years ago. The randomised data was presented with insufficient clarity to allow for inclusion in a meta-analysis.

\section{Primary Outcome}

Number of participants suffering an affective episode by the end of the study period

Both studies (Cabrera 1986; Wildgrube 1990) used life chart mapping to depict affective recurrences pre- and postrandomisation. Extracting the number of affective recurrences from the life chart maps could not be performed with confidence, as in some cases the boundaries between distinct episodes could not be easily distinguished from switches of affective states or partial recoveries. In the Wildgrube 1990 study, the randomised and the non-randomised group were presented together and the respective groups were not identifiable, despite contacting the author of the paper.

\section{Secondary Outcomes}

1. Efficacy of oxcarbazepine in preventing/attenuating further episodes of affective disorder

Neither study provided data for this outcome

\section{General and social functioning}

Neither study provided data for this outcome

\section{Treatment acceptability}

The numbers of participants dropping out of treatment early was used as a measure of acceptability of treatment. As mentioned in the previous section, in Cabrera 1986, all participants on oxcarbazepine ( $n=4,100 \%$ ) dropped out (between 6 to 22 months) while only $17 \%$ of the patients on lithium dropped out. Reasons for dropout were as follows: oxcarbazepine $(n=4$, three were non-compliant, one developed leucocytopenia), lithium ( $n=6$, one dropped out, having developed thyroid dysfunction). Wildgrube
1990 reported similarly high discontinuation rates in participants on oxcarbazepine $(67 \%)$ and lower rates for patients on lithium $(33 \%)$. Again, the results from the randomised and the openlabel groups were presented together. Causes of dropouts were: oxcarbazepine $(n=9$, one developed leucocytopenia, one had cancer, two rejected treatment, one had no therapeutic effect and one was non-compliant), lithium ( $n=9$, one had general emotional indifference, one intended pregnancy and one rejected treatment).

\section{Adverse effects}

In the Cabrera 1986 study, with regard to side effects, one subject in the oxcarbazepine group suffered an episode of nausea. For those on lithium, there were two episodes of tremor, two of thirst, one of polyuria, two of diarrhoea, two of nausea, two of tiredness, two of weight gain and three of increased appetite. In the Wildgrube 1990 study, amongst the eight participants on oxcarbazepine, there were three episodes of temporary rash and two episodes of ataxia. Five of the seven participants on lithium experienced adverse effects including diarrhoea, goiter and polydipsia.

\section{Mortality rates}

There was no reported mortality in neither of the studies.

\section{Publication bias}

The presence of publication bias was not examined in this systematic review as too few studies were found to construct a meaningful funnel plot.

\section{DISCUSSION}

This systematic review did not find any randomised controlled trial data of sufficient methodological rigour or reported with sufficient clarity to assess the efficacy of oxcarbazepine in the treatment for the prevention of affective relapses in the maintenance treatment of bipolar disorder. The findings of this review are consistent with those of Popova 2007, who pointed to the methodological shortcomings of existing trials.

The existing trials are small, include participants with bipolar and schizoaffective disorder and used both open-label nonrandomised and randomised treatment allocation. Both trials scored poorly on measures of methodological quality. One trial report (Wildgrube 1990) did not separate data from randomised from non-randomised participants. Although Cabrera 1986 did differentiate randomised and non-randomised arms, it was difficult to ascertain the exact number of affective recurrences as this data was presented as life chart mapping. With regard to acceptability, adverse effects experienced by participants were neither serious nor life threatening. However, in both trials, dropout rates in participants on oxcarbazepine were higher than in those on lithium.

\section{AUTHORS' CONCLUSIONS}

\section{Implications for practice}

There is insufficient published evidence from randomised controlled trials on which to base any recommendations regarding the use of oxcarbazepine in maintenance phase of bipolar illness, either in monotherapy or as an adjunctive treatment. Despite this, oxcarbazepine is used clinically in the treatment of bipolar disorder as an alternative to carbamazepine because of its favourable pharmacokinetic profile: its use is suggested in bipolar treatment guidelines (APA 2002; Goodwin 2003). Given the need for new agents in bipolar disorder and the potentially superior 
pharmacokinetic profile offered by oxcarbazepine in comparison to lithium, a methodologically robust evidence base is required.

\section{Implications for research}

There is a need for data from randomised controlled trials examining the efficacy and acceptability of oxcarbazepine in the treatment and prevention of relapse of different affective states during the maintenance treatment of bipolar disorder Oxcarbazepine is now a generic medication. Other related medications such as licarbazepine and eslicarbazepine have been suggested as possible useful treatments for bipolar disorder, but require further study (Popova 2007).

This review highlights the need for studies to be designed well and reported with clarity. As previously discussed (Young 2006), the design of trials should incorporate the following general features. An appropriate method of treatment assignment should be used in order to prevent knowledge of the participant's treatment allocation prior to it taking place. Where possible, that allocation should be concealed from the participant and the assessor throughout the trial, although this may not be practicable. The outcome in all participants allocated to each treatment should be reported, including those who drop out early. In those who do drop out early, the reason should be recorded. These factors are discussed in more detail in the Cochrane Handbook (Higgins 2005). Careful consideration should be given to the number of participants required to demonstrate a statistically significant difference between the two treatments in the chosen primary outcome measure. Outcome measures should include factors that are relevant to patients, such as potential improvements in social function and the length of admissions to hospital.

In bipolar disorder studies, particular attention should be given to the reporting of the characteristics of the participants' illnesses, their previous treatment and the withdrawal of any psychotropic medication before and during the trial period.

\section{ACKNOWLEDGEMENTS}

The authors wish to gratefully acknowledge the help of CCDAN editorial staff and editorial team with the review. We would like to particularly acknowledge the help provided by Hugh McGuire for the database searches. 


\section{REFERE N CES}

\section{References to studies included in this review}

\section{Cabrera 1986 \{published data only\}}

Cabrera JF, Muhlbauer HD, Schley J, Stoll KD, Muller Oerlinghausen B. Long term randomized clinical trial on oxcarbazepine vs lithium in bipolar and schizoaffective disorders: Preliminary results. Pharmacopsychiatry 1986;19:282-3.

\section{Wildgrube 1990 \{published data only\}}

Wildgrube $\mathrm{C}$. Case studies on prophylactic long term effects of oxcarbazepine in recurrent affective disorder. International Clinical Psychopharmacology 1990;5 Suppl 1:89-94.

\section{References to studies excluded from this review}

Reinstein 2003 \{published data only\}

Reinstein MJ, Sonnenberg JG, Hedberg TG, Jones LE, Reyngold P. Oxcarbazepine versus divalproex sodium for the continuing treatment of mania. Clinical Drug Investigation 2003;23(10):671-7.

Wagner 2006b \{published data only\}

* Wagner KD, Kowatch RA, Emslie GJ, Findling RL, Wilens TE, McCague K, et al. A double-blind, randomized, placebocontrolled trial of oxcarbazepine in the treatment of bipolar disorder in children and adolescents. American Journal of Psychiatry 2006;163(7):1179-86.

\section{Additional references}

\section{Akiskal 2000}

Akiskal HS, Bourgeois ML, Angst J, Post R, Moller H, Hirschfeld R. Re-evaluating the prevalence of and diagnostic composition within the broad clinical spectrum of bipolar disorders. Journal of Affective Disorders 2000;59 Suppl 1:S5-S30.

\section{Altman 1996}

Altman D, Bland M. Detecting skewness from summary information. BMJ 1996;313:706.

\section{Angst 2000}

Angst J, Sellaro R. Historical perspectives and natural history of bipolar disorder. Biological Psychiatry 2000;48:445-57.

\section{APA 1994}

American Psychiatric Association. Diagnostic and Statistical Manual of Mental Disorders (DSM-IV). 4th Edition. Washington, DC: American Psychiatric Association, 1994.

\section{APA 2002}

American Psychiatic Associaton. Practice Guideline for the Treatment of Patients with Bipolar Disorder 2nd Edition. Online addition: http://www.psych.org/psych_pract/treatg/pg/ Bipolar2ePG_05-15-06.pdf 2002.

\section{Benedetti 2004}

Benedetti A, Lattanzi L, Pini S, Musetti L, Dell'Osso L, Cassano GB. Oxcarbazepine as add-on treatment in patients with bipolar, manic, mixed or depressive episode. Journal of Affective Disorders 2004;79:273-7.

\section{BNF 2007}

Various. British National Formulary. March. London: BMJ and RPS publishing, 2007.

\section{Bowden 1996}

Bowden CL. Role of newer medications for bipolar disorder. Journal of Clinical Psychopharmacology 1996;16(2 Suppl 1):48S-55S

\section{Cohen 1960}

Cohen J. A coefficient of agreement for nominal scales. Educational and Psychological Measurement 1960;20:37-46.

\section{DerSimonian 1986}

DerSimonian R, Laird N. Meta-analysis in clinical trials. Controlled Clinical Trials 1987;7:177-88.

\section{Dietrich 2001}

Dietrich DE, Kropp S, Emrich HM. Oxcarbazepine in affective and schizoaffective disorders. Pharmacopsychiatry 2001;34:242-50.

\section{Dong 2005}

Dong X, Ilo E, Leppik IE, White J, Rarick J. Hyponatremia from oxcarbazepine and carbamazepine. Neurology 2005;65:1976-8.

\section{Fleiss 1981}

Fleiss. Statistical Methods for Rates and Proportions. 2nd Edition. New York, NY: Wiley, 1981.

\section{Goodwin 1994}

Goodwin GM. Recurrence of mania after lithium withdrawal. Implications for the use of lithium in the treatment of bipolar affective disorder. British Journal of Psychiatry 1994;164:149-52.

\section{Goodwin 2003}

Goodwin GM. Evidence-based guidelines for treating bipolar disorder: recommendations from the British Association for Psychopharmacology. British Journal of Psychopharmacology 2003;17(2):149-73.

\section{Higgins 2005}

Higgins JPT, Green S. Cochrane Handbook for Systematic Reviews of Interventions 4.2.4. In The Cochrane Library. Chichester, UK: John Wiley \& Sons, Ltd, 2005.

\section{Hirschfeld 2004}

Hirschfeld R, Kasper S. A review of the evidence for carbamazepine and oxcarbazepine in the treatment of bipolar disorder. International Journal of Neuropsychopharmacology 2000;7:502-22. 


\section{Isojarvi 1994}

Isojarvi JI, Pakarinen AJ, Rautio A, Pelkonen O, Myllyla VV. Liver enzyme induction and serum lipid levels after replacement of carbamazepine with oxcarbazepine.. Epilepsia 1994;35(6):1217-20.

\section{Jadad 1996}

Jadad AR, Moore RA, Carroll D, Jenkinson C, Reynolds DJ, Gavaghan DJ, et al. Assessing the quality of reports of randomized clinical trials: is blinding necessary?. Controlled Clinical Trials 1996;17(1):1-12.

\section{NICE 2006}

NICE guidelines: Bipolar disorder. The management of bipolar disorder in adults, children and adolescents, in primary and secondary care Guidance type: Clinical guideline. http:// www.nice.org.uk/CG38 2006.

\section{Okuma 1981}

Okuma T, Inanaga K, Otsuki S, Sarai K, Takahashi R, Hazama H, et al. A preliminary double-blind study on the efficacy of carbamazepine in prophylaxis of manic-depressive illness. Psychopharmacology 1981;73:95-96.

\section{Oxman 1995}

Oxman A. Preparing and maintaining systematic reviews. Cochrane Collaboration Handbook. Vol. section VI, updated 14th July, Oxford, 1995.

\section{PDF 2001}

Various. Physicians Desk Reference. 5th Edition. Montvale, NJ: Medical Economics Co, 2001.

\section{Popova 2007}

Popova E, Leighton C, Bernabarre A, Bernardo M, Vieta E. Oxcarbazepine in the treatment of bipolar and schizoaffective disorders. Expert Review of Neurotherapeutics 2007;7(6):617-26.

\section{Schulz 1995}

Schulz KF, Chalmers I, Hayes RJ, Altman DG. Empirical evidence of bias. Dimensions of methodological quality associated with estimates of treatment effects in controlled trials. JAMA 1995;273(5):408-12.

\section{Smith 2007}

Smith LA, Cornelius V, Warnock A, Tacchi MJ, Taylor D. Pharmacological interventions for acute bipolar mania: a systematic review of randomized placebo-controlled trials. Bipolar Disorder 2007;9(6):551-60.

\section{WHO 1992}

World Health Organisation. The World Health Organisation. The ICD-10 Classification of mental and behavioural disorders. Clinical descriptions and diagnostic guidelines. Geneva: World Health Organisation, 1992.

\section{Yatham 2005}

Yatham LN, Kennedy SH, O'Donovan C, Parikh S, MacQueen G, Mclntyre R, et al. Canadian Network for Mood and Anxiety Treatments. Canadian Network for Mood and Anxiety Treatments (CANMAT) guidelines for the management of patients with bipolar disorder: consensus and controversies. Bipolar Disorders 2005;7 Suppl 3:5-69.

\section{Yatham 2006}

Yatham LN, Kennedy SH, O'Donovan C, Parikh SV, MacQueen G, McIntyre RS, et al. Canadian Network for Mood and Anxiety Treatments (CANMAT) guidelines for the management of patients with bipolar disorder: update 2007. Bipolar Disorders 2006;8(6):721-39.

\section{Young 2006}

Young AH, Geddes JR, Macritchie K, Rao SN, Watson S, Vasudev A. Tiagabine in the treatment of acute affective episodes in bipolar disorder: efficacy and acceptability. Cochrane Database of Systematic Reviews 2006, Issue CD004694.

* Indicates the major publication for the study

\section{CHARACTERISTICS OF STUDIES}

Characteristics of included studies [ordered by study ID]

\section{Cabrera 1986}

\begin{tabular}{ll}
\hline Methods & Randomised controlled trial \\
\hline Participants & Bipolar disorder and schizoaffective disorder \\
\hline Interventions & 4 on oxcarbazepine, 6 on lithium \\
\hline Outcomes & Relapse of disorder \\
\hline Notes & $\begin{array}{l}36 \text { month study . Text documented } 15 \text { patients being initally randomised. Rest of five patients not ac- } \\
\text { counted for. All patients on oxcarbazepine dropped out, however no mention of handling of drop outs } \\
\text { in final analysis. No subgroup analysis possible as patients having schizoaffective disorder not delineat- }\end{array}$
\end{tabular}


Cabrera 1986 (Continued)

ed. All patients discontinued therapy before two years itself, reason for discontinuation for individual patients not described.

\section{Risk of bias}

\begin{tabular}{lll}
\hline Bias & Authors' judgement & Support for judgement \\
\hline Allocation concealment? & High risk & C - Inadequate \\
\hline
\end{tabular}

Wildgrube 1990

\begin{tabular}{ll}
\hline Methods & Trial with both randomised and open label arms \\
\hline Participants & Bipolar disorder and schizoaffective disorder \\
\hline Interventions & 8 on oxcarbazepine, 7 on lithium. 5 of these were open label \\
\hline Outcomes & Relapse of disorder \\
\hline Notes & $\begin{array}{l}\text { 33 month study . Method of randomisation was not clear. Method of analysing open label patients, if } \\
\text { analysed separately, from randomised group was not described. }\end{array}$ \\
\hline Risk of bias & Authors' judgement Support for judgement \\
\hline Bias & High risk $\quad$ C - Inadequate \\
\hline Allocation concealment? &
\end{tabular}

Characteristics of excluded studies [ordered by study ID]

\begin{tabular}{ll}
\hline Study & Reason for exclusion \\
\hline Reinstein 2003 & Study of acute mania \\
\hline Wagner 2006b & Study of acute mania \\
\hline
\end{tabular}

\section{ADDITIONAL TABLES}

Table 1. Medline search strategy

\begin{tabular}{ll}
\hline Numbers & search strategy \\
\hline 1 & randomized-controlled-trial.pt. \\
\hline 2 & controlled clinical trial.pt. \\
\hline 3 & randomized controlled trials.sh. \\
\hline 4 & random allocation.sh. \\
\hline \hline
\end{tabular}


Table 1. Medline search strategy (Continued)

5

6

7

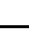

8

9

10

11

12

13

14

15

16

17

18

19

20

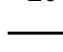

21

22

double blind method.sh

single blind method.sh.

clinical trial.pt.

exp Clinical trials/

(clin\$ adj25 trial\$).ti,ab.

((singl\$ or doubl\$ or tripl\$ or trebl\$) adj25 (blind\$ or mask\$ ordummy\$)).mp. [mp=title, abstract, cas registry/ec number word, mesh subject heading]

placebos.sh.

placebo\$.ti,ab

random $\$$.ti,ab.

research design.sh.

comparative study.sh.

exp evaluation studies/

follow up studies.sh

prospective studies.sh.

(control\$ or prospectiv\$ or volunteer\$).ti,ab.

1 or 2 or 3 or 4 or 5 or 6 or 7 or 8 or 9 or 10 or 11 or 12 or 13 or 14 or 15 or 16 or 17 or 18 or 19

(animal not human).sh.

$20 \operatorname{not} 21$

This will be combined with (oxcarbazepine, trileptal)

Table 2. EMBASE search strategy

\begin{tabular}{ll}
\hline Numbers & Search strategy \\
\hline 1 & Controlled study/ \\
\hline 2 & Clinical trial/ \\
\hline 3 & Major clinical study/ \\
\hline 4 & Randomized controlled trial/ \\
\hline 5 & Double blind procedure/ \\
\hline 6 & Clinical article/ \\
\hline \hline
\end{tabular}

Oxcarbazepine in the maintenance treatment of bipolar disorder (Review)

Copyright $\odot 2010$ The Cochrane Collaboration. Published by John Wiley \& Sons, Ltd. 
Table 2. EMBASE search strategy (Continued)

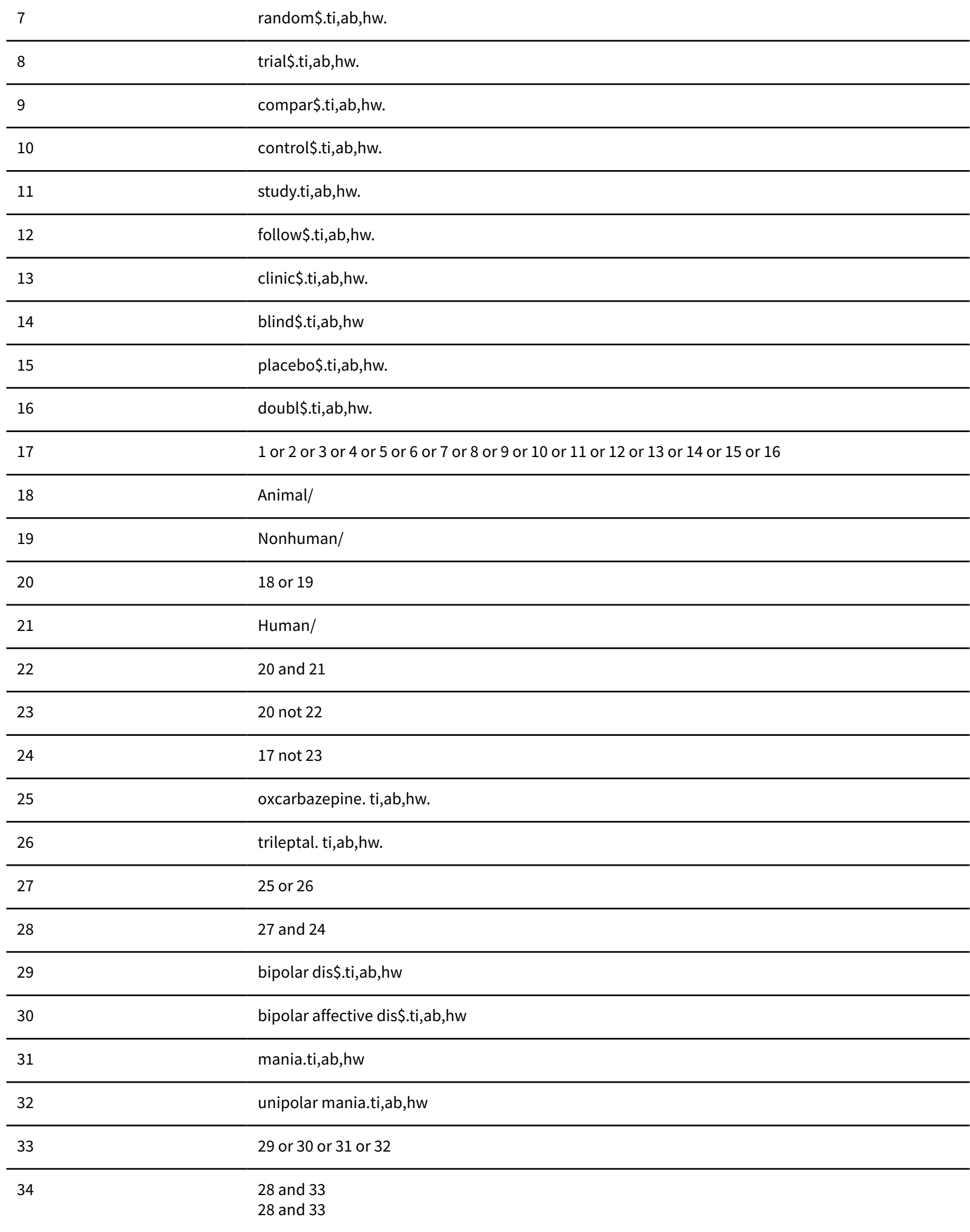


Table 2. EMBASE search strategy (Continued)

\section{Table 3. Psyclnfo search strategy}

\begin{tabular}{|c|c|}
\hline Numbers & Search strategy \\
\hline 1 & random* \\
\hline 2 & singl* \\
\hline 3 & doubl $^{*}$ \\
\hline 4 & tripl $^{\star}$ \\
\hline 5 & trebl $^{*}$ \\
\hline 6 & blind* \\
\hline 7 & mask $^{*}$ \\
\hline 8 & (\#2 or \#3 or \#4 or \#5) near (\#6 or \#7) \\
\hline 9 & crossover \\
\hline 10 & cross-over \\
\hline 11 & versus \\
\hline 12 & vs \\
\hline 13 & $\# 1$ or \#8 or \#9 or \#10 or \#11 or \#12 \\
\hline 14 & '"oxcarbazepine"in DE \\
\hline 15 & Oxcarb* \\
\hline 16 & Trileptal \\
\hline 17 & Oxcarb* or trileptal \\
\hline 18 & $\# 17$ or \#14 \\
\hline 19 & $\# 13$ and \#18 \\
\hline
\end{tabular}

WHAT'S NEW

\begin{tabular}{lll}
\hline Date & Event & Description \\
\hline 3 November 2008 & Amended & Converted to new review format. \\
\hline
\end{tabular}




\section{H IST O RY}

Protocol first published: Issue 1, 2004

Review first published: Issue 1, 2008

\begin{tabular}{lll}
\hline Date & Event & Description \\
\hline 1 September 2007 & $\begin{array}{l}\text { New citation required and conclusions } \\
\text { have changed }\end{array}$ & Substantive amendment \\
\hline
\end{tabular}

\section{CONTRIBUTIONS OFAUTHORS}

Dr Akshya Vasudev (AV) co-wrote the protocol, performed the literature search, the selection of trials, and co-wrote the review. Dr Macritchie (KM) co-wrote the protocol, performed the selection of trials, and co-wrote the review.

Dr Stuart Watson (SW) performed the quality assessment of the trials.

Prof AH Young $(\mathrm{AH})$ commented on the protocol, performed quality assessment and commented on the final version of the review. Prof JR Geddes (JRG) devised the original protocol for systematic reviews on pharmacological interventions in bipolar disorder, on which the protocol was based.

\section{DECLARATIONS OF INTEREST}

None of the reviewers is an employee of or has shares in a pharmaceutical company. Professor Young, Dr Watson, Dr Vasudev and Dr Macritchie have spoken at meetings and attended conferences sponsored by various pharmaceutical companies and have participated in trials sponsored by pharmaceutical companies. Professor Young has advised various pharmaceutical companies on a fee for service basis, including Novartis Ltd.

\section{SOURCES OF SUPPORT}

\section{Internal sources}

- Department of Psychiatry, Royal Victoria Infirmary, Newcastle upon Tyne, UK.

\section{External sources}

- No sources of support supplied

\section{IN DEX TERMS}

\section{Medical Subject Headings (MeSH)}

Antimanic Agents [ ${ }^{\star}$ therapeutic use]; Bipolar Disorder [ ${ }^{\star}$ drug therapy]; Carbamazepine [*analogs \& derivatives] [therapeutic use]; Lithium Compounds [therapeutic use]; Oxcarbazepine; Randomized Controlled Trials as Topic; Secondary Prevention

\section{MeSH check words}

Humans 